Article

\title{
Preparation and Characterization of Waterborne UV Lacquer Product Modified by Zinc Oxide with Flower Shape
}

\author{
Yan $W u^{1,2, *}$, Xinyu Wu ${ }^{1,2}$, Feng Yang ${ }^{3, *}$ and Jiaoyou Ye ${ }^{4}$ \\ 1 College of Furnishings and Industrial Design, Nanjing Forestry University, Nanjing 210037, China; \\ aprilwu2019@163.com \\ 2 Co-Innovation Center of Efficient Processing and Utilization of Forest Resources, Nanjing Forestry \\ University, Nanjing 210037, China \\ 3 Fashion Accessory Art and Engineering College, Beijing Institute of Fashion Technology, Beijing 100029, \\ China \\ 4 DeHua TB New Decoration Material Co. Ltd., Deqing 313200, China; yejiaoyou2020@163.com \\ * Correspondence: wuyan@njfu.edu.cn (Y.W.); yangfeng@bift.edu.cn (F.Y.)
}

Received: 3 March 2020; Accepted: 14 March 2020; Published: 17 March 2020

\begin{abstract}
In this paper, the waterborne UV lacquer product (WUV) was used as the main raw material, zinc oxide $(\mathrm{ZnO})$ was used as the additive, and the stearic acid as the surface modifier. According to the method of spraying coating on the surface of poplar wood (Populus tomentosa), a simple and efficient preparation method was carried out to generate a super-hydrophobic surface and enhance the erosion resistance of the coating. By testing, the contact angle (CA) of water on the coating surface can reach $158.4^{\circ}$. The microstructure and chemical composition of the surface of coatings were studied by scanning electron microscope (SEM), Fourier transform infrared spectroscopy (FT-IR), and X-ray diffraction (XRD). The results showed that under acidic conditions, the non-polar long chain alkyl group of stearic acid vapor molecule reacted with the hydroxyl group in acetic acid, the metal ions of the $\mathrm{ZnO}$ were displaced to the stearic acid and generated globular zinc stearate $\left(\mathrm{C}_{36} \mathrm{H}_{70} \mathrm{O}_{4} \mathrm{Zn}\right)$. The hydrophobic groups $-\mathrm{CH}_{3}$ were grafted to the surface of zinc stearate (ZnSt2) particles and the micro/nano level of multistage flower zinc stearate coarse structure was successfully constructed on the surface of poplar wood, which endowed it with superhydrophobic properties. It is shown that the coating has good waterproof and erosion resistance.
\end{abstract}

Keywords: poplar wood; waterborne UV lacquer product; wood modification; contact angle; spectroscopy; super-hydrophobic coating

\section{Introduction}

Waterborne UV lacquer product (WUV) is a kind of coating which realizes crosslinking curable by UV irradiation [1]. It does not contain volatile toxic substances or irritating gases [2-4]. WUV combines UV-cured technology with waterborne polymer technology [5,6], which not only saves energy and protects environmental but also has the advantages of fast curing speed, pipeline production and high production efficiency [7,8]. The main component of WUV is waterborne acrylic resin [9]. It has the advantages of light color, high solid content, and strong adhesion, but its hardness, wear resistance, and mechanical properties limit its use [10-12]. However, due to the water-based acrylic resin with water as the dispersion medium, the phenomenon of incomplete curing is easy to occur during curing, and the residual water-based additives lead to poor water resistance of the coating. In addition, the evaporation of water requires more heat, which asks higher requirements during the drying process of the coating. In order to better play the application of UV cured coatings in the field of wood, 
the ultra-hydrophobic modification [13] and durability enhancement [14] are needed to improve the properties of WUV, so as to better meet the production and use requirements. Zhong et al. [15] used maleic anhydride and silicon modified waterborne alkyd resin, and prepared fluoro-acrylate resin by micro-emulsion polymerization without surfactant. The modified resin has better mechanical stability and corrosion resistance due to its larger contact angle with water. Saladino et al. prepared for the silica/PMMA nanocomposites with different silica quantities by a melt compounding method and systematically investigated it as a function of silica amount from 1 to $5 \mathrm{wt} \%$. Results showed that silica nanoparticles are well dispersed in the polymeric matrix whose structure remains amorphous. The degradation of the polymer occurs at higher temperature in the presence of silica because of the interaction between the two components [16].

As a kind of inorganic material, zinc oxide nanoparticles have diversified morphology and excellent physicochemical properties [17]. Therefore, $\mathrm{ZnO}$ nanoparticles are a common packing, they are low cost [18-20], harmless to the environment [19], and have excellent photoelectric performance and rich form. Therefore, they have a broad application prospect in coatings [21-23], sensors [24,25], photoelectric material [26-28], medicine [20], and many other fields [29]. For example, Zahra et al. [30] used mixed $\mathrm{ZnO} / \mathrm{GO}$ nanostructures to modify the surface of low carbon steel before acrylic resin coating. Through the structural properties and interactions between the oxygen-containing groups of $\mathrm{ZnO}$ and GO structures, the corrosion resistance of low carbon steel was improved. Zhou et al. [31] prepared the nano-hydroxyapatite/ZnO coating on biodegradable $\mathrm{Mg}$-Zn-Ca block metallic glass by one-step hydrothermal method. Due to the presence of $\mathrm{ZnO}$ in the coating, the antibacterial rate of BMG in vitro was close to $100 \%$. Guo et al. prepared two coatings on the surface of spruce panels, the first coating was coated by UV light absorbing $\mathrm{ZnO}$ and an additional hydrophobic layer of stearic acid, which endowed the wooden panels with water repellence as well as protected the $\mathrm{ZnO}$ coating from erosion due to rain. The second coating was based on a thin $\mathrm{TiO}_{2}$ layer attached to the wood surface, which aimed to avoid a pronounced initial color change induced by the coating itself [32]. Nair et al. prepared a stable dispersion of nanoparticles of three metal oxides, zinc oxide $(\mathrm{ZnO})$, cerium oxide $\left(\mathrm{CeO}_{2}\right)$, and titanium dioxide $\left(\mathrm{TiO}_{2}\right)$ by propylene glycol (PG) through ultrasonication. The stability test of the coating was measured by UV-vis absorption spectroscopy and an accelerated weathering tester. Results shown that the increase in concentration of nanoparticles in the dispersion imparted higher resistance to UV induced degradation [33].

In wood science, the utilization of wood can be improved by changing its dimensional stability, flammability, biodegradability, and other properties [34]. Tuong et al. treated the acacia hybrid wood with $\mathrm{TiO}_{2}$ impregnation through the combination of pressure impregnation and hydrothermal post-treatment. Results showed that the color stability against UV irradiation of the $\mathrm{TiO}_{2}$ impregnated wood was significantly improved than that of the untreated acacia hybrid wood. $\mathrm{The}_{\mathrm{TiO}} \mathrm{O}_{2}$ nanoparticles were located on the inner surfaces of the wood vessels and it could improve the UV resistance of fabricated wood samples [35]. Yu et al. constructed $\mathrm{ZnO}$ nanostructures on the surface of solid wood via a simple two-step process consisting of generation of $\mathrm{ZnO}$ seeds on the wood surface followed by a solution treatment to promote crystal growth. Accelerated weathering was used to evaluate the photostability of treated wood. Results showed that the photostability of the treated wood was greatly enhanced [36].

The super-hydrophobic modification of WUV can make it have the properties of self-cleaning [37,38], antifouling [38] and water resistance [39] and improve the erosion resistance [3,40-43] of the coating, so that the wood material will possess a higher use value [44-46]. Yang et al. [47] soaked the poplar wood in a compound solution of maleic rosin and ethanol for $24 \mathrm{~h}$. After being taken out and dried, the sample was then soaked again in the solution of $\mathrm{TiO}_{2}$ and modifier to obtain a super-hydrophobic wood with a contact angle up to $157^{\circ}$. After soaking the modified poplar in water for a week, irradiation under the hot sun for a week or boiling at $100^{\circ} \mathrm{C}$, the wood surface still has super hydrophobicity. Gao et al. prepared superhydrophilic and underwater superoleophobic poly by salt-induced phase inversion method. This kind of poly can quickly and efficiently separate 
the oil-water mixture system from the emulsified oil-water system, and the separation property is stable. After repeated use, the separation efficiency of the oil-water mixture was above $98 \%$, and that of the oil-water emulsion is above $91 \%$, which can be widely used in the oil-water mixture system and emulsified oil-water system [48]. Wang et al. [49] impregnated wood into a mixture of zinc acetate dihydrate and triethylamine, constructed a $\mathrm{ZnO}$ coating with roughness on the wood surface, and modified the coating surface with stearic acid to obtain a super-hydrophobic coating with low surface energy. The superhydrophobic coating remained superhydrophobic after drying at $60{ }^{\circ} \mathrm{C}$ for a month or soaking in deionized water for a week, showing good air stability and erosion resistance, which retained the natural appearance of wood while minimizing maintenance intervals. Poplar wood is a kind of fast growing wood, which is sustainable, biodegradable, biocompatible [34], rich in natural resources and low in price. It is usually used in furniture manufacturing. In this paper, $\mathrm{ZnO}$ nanoparticles (ZnO NPs) were used as the modifier to prepare for a superhydrophobic WUV coating on poplar wood, which retained the natural appearance of wood while minimizing maintenance intervals $[32,50]$. The possibility of large-scale application of this low-cost and environmentally friendly superhydrophobic surface preparation technology is discussed theoretically. This study is of guiding significance to the application of functional materials with superhydrophobicity.

\section{Experimental Part}

\subsection{Materials}

The poplar wood (Populus tomentosa) cut from the longitudinal section with the size of $20 \mathrm{~mm}$ long $\times 20 \mathrm{~mm}$ wide $\times 2 \mathrm{~mm}$ thick was supplied by Yihua Lifestyle Technology Co., Ltd., Shantou, China. Its moisture content was $9.9 \%$ and the absolute dry density was $298 \mathrm{~kg} / \mathrm{m}^{3}$. The above data was tested at 10 a.m. in winter, in an environment of $25{ }^{\circ} \mathrm{C}$ and the relative humidity of $46 \%$. The waterborne UV lacquer product (A185721006) was purchased from Huzhou Dazhou Polymer Material Co., Ltd., Huzhou, China. Ethyl acetate (99.5\%) and acetic acid $\left(\mathrm{CH}_{3} \mathrm{COOH}, 99.5 \%\right)$ were provided by Nanjing Chemical Reagent Co., Ltd., Nanjing, China. Zinc oxide (ZnO) was obtained from Xilong Scientific Co., Ltd.,Guangzhou, China. Anhydrous ethanol (99.7\%), n-hexane (99\%) and TBOT (98\%) was purchased from Sinopharm Group, Shanghai, China. Stearic acid $\left(\mathrm{C}_{18} \mathrm{H}_{36} \mathrm{O}_{2}\right)$ was provided from Yonghua Chemical Technology Co., Ltd, Changshu, China.

\subsection{Experimental Method}

First, the poplar wood was dipped in anhydrous ethanol and distilled water respectively and experienced sonication by an ultrasonic crusher (Misonix, Inc., New York, USA) for $1 \mathrm{~h}$, and then the treated wood was dried to absolute dry condition at $100{ }^{\circ} \mathrm{C}$ by a constant temperature blast drying oven (Shanghai Xinmiao Medical Devices Co., Ltd., Shanghai, China). $10 \mathrm{~g}$ WUV and $6 \mathrm{~g}$ ZnO powder was added into $13 \mathrm{~mL}$ ethyl acetate and the mixed solution was magnetically stirred by a magnetic stirrer (Yinyu High-tech Instrument factory, Gongyi, China) for $45 \mathrm{~min}$, so that the WUV and ZnO powder were evenly dispersed in ethyl acetate. The obtained ZnO/WUV lacquer was sprayed onto dried poplar wood surface with a high-pressure electric spraying machine (Pritzker Power Tools, Ningbo, China) at a distance of about $15-20 \mathrm{~cm}$. Two layers of UV lacquer product were applied to the poplar wood surface. The ZnO/WUV lacquer was cured under ultraviolet lamp (Wuxi Jinhua Test Equipment Co., Ltd, Wuxi, China) for $3.5 \mathrm{~min}$ and dried at $85^{\circ} \mathrm{C}$ for $4 \mathrm{~h}$ to obtain $\mathrm{ZnO} / \mathrm{WUV}$ coating.

Then the anhydrous ethanol was used as dispersant, $20 \mathrm{~mL}$ stearic acid and acetic acid were allocated as mixture under $70{ }^{\circ} \mathrm{C}$. The solution was centrifuged at $4000 \mathrm{r} / \mathrm{min}$ with a centrifuge (Shanghai Anting Scientific Instrument Factory, Shanghai, China) for $5 \mathrm{~min}$. The sonicated mixture was cooled to room temperature, and the $\mathrm{ZnO} / \mathrm{WUV}$ sample was dipped into the mixture for 200 seconds before being removed. The multistage flower zinc stearate/waterborne UV lacquer super-hydrophobic coating (ZnSt2/WUV) was obtained after drying. The diagram of modification process of ZnO/WUV and ZnSt2/WUV coatings is shown in Figure 1. 


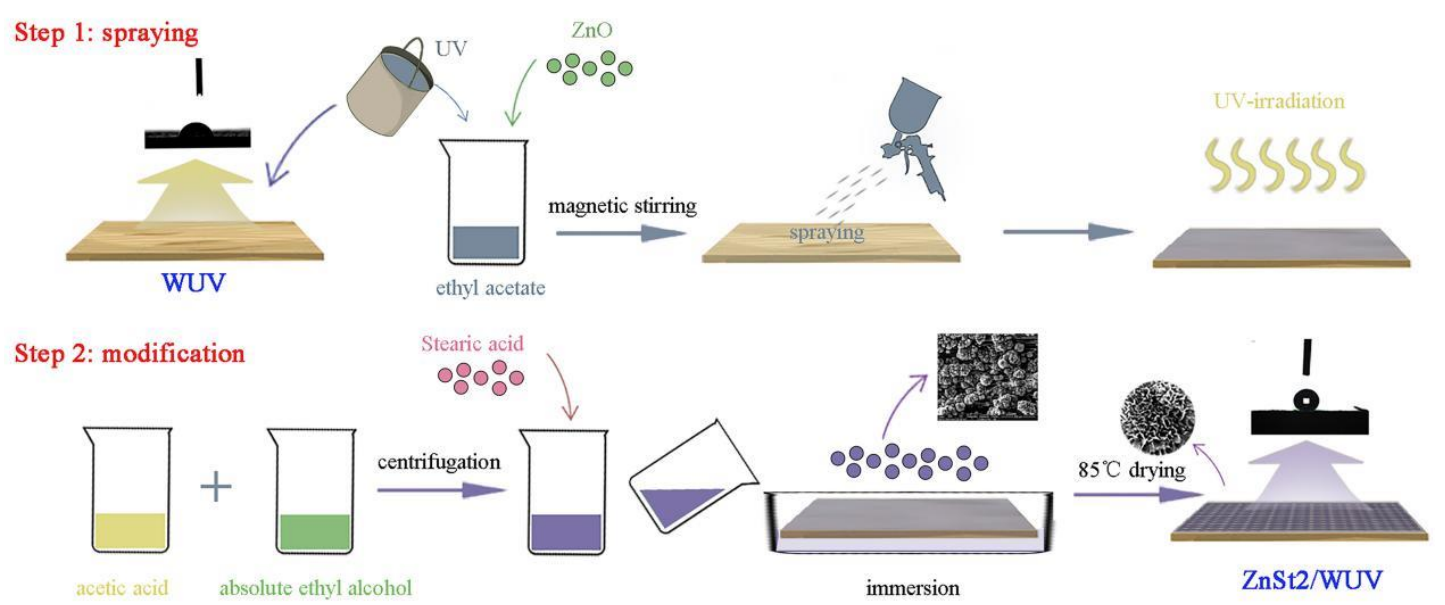

Figure 1. Diagram of modification process.

\subsection{Contact Angle (CA) Test}

The contact angle of water on the cross section of ZnSt2/WUV was measured by Theta t200 Optical contact goniometer (Sweden baiorin technology Co. Ltd., Gothenburg, Swedish). After drying, the WUV and ZnSt2/WUV samples were placed on the loading platform. About $2 \mu \mathrm{L}$ of deionized water was dripped on the surface of the samples under test. The sample was tested three times in parallel at different locations.

\subsection{SEM}

After the prepared WUV and ZnSt2/WUV samples were dried, thin slices with a width of about $5 \mathrm{~mm}$ and a thickness of about $2 \mathrm{~mm}$ were cut and fixed to the conductive adhesive on which the samples were placed with tweezers. The samples were sprayed with gold for $30 \mathrm{~s}$ with a vacuum plating apparatus. The surface and internal morphology of the samples were observed with an environmental QUANTA 200 SEM (FEI Company, Hillsboro, OR, USA) at 3 kV voltage.

\subsection{FTIR and XRD}

A Vertex 80V infrared spectrum analyzer (Germany Bruker Co., Ltd., Karlsruhe, Germany) was used to determine the functional groups of the $\mathrm{ZnSt} 2 / \mathrm{WUV}$, and the wave number range was set at $500-4000 \mathrm{~cm}^{-1}$. AXIS UltraDLD XRD (Nippon Koji Co. Ltd, Osaka, Japan) was used to characterize the internal molecular structure of the sample. The scanning speed was set from $5^{\circ}$ to $70^{\circ}$ [51], the acceleration voltage was $40 \mathrm{kV}$, and the impressed current was $30 \mathrm{~mA}$.

\subsection{Different $p H$ Values of Solution and Organic Solvent Immersion Test}

ZnSt2/WUV was soaked in the solutions with the $\mathrm{pH}$ values of 2, 4, 7, 9, 12, respectively and dried after a period of time [52]. Similarly, the samples were soaked in different organic solvents [53], dried after a period of time, and the contact angle of water on two samples in the same reagent were measured and the average value of them was obtained as the final data.

\subsection{Water Resistance Test}

In order to determine whether the ZnSt2/WUV coating had good water resistance, two samples for each of WUV and ZnSt2/WUV were impregnated in distilled water, and then which were taken out and weighed after a period of time, and the water absorption before and after modification was calculated by using Equation (1):

$$
\mathrm{WA}(\%)=\left(m_{a i}-m_{b i}\right) / m_{b i} \times 100 \%
$$


where $m_{\mathrm{bi}}$ and $m_{\mathrm{ai}}$ represent the film weights before and after absorbed water, respectively [15].

\section{Results and Discussion}

\subsection{Contact Angle (CA) Test}

By testing, the contact angles of water on the WUV and ZnSt2/WUV (Table 1) coating samples were $68.2^{\circ}$ and $158.4^{\circ}$, respectively. Compared with the WUV coating, the ZnSt2/WUV coating had the property of superhydrophobicity.

Table 1. Image of contact angle (A: WUV; B: ZnSt2/WUV)

\begin{tabular}{ll}
\hline Name of the Coating & $\begin{array}{c}\text { Contact Angle of Water on the } \\
\text { Coating Surface }\left({ }^{\circ}\right)\end{array}$ \\
$\mathrm{WUV}$ & Image of Contact Angle \\
$\mathrm{ZnSt} 2 / \mathrm{WUV}$ & 158.4 \\
\hline
\end{tabular}

\subsection{SEM}

The surface microstructure of WUV and ZnSt2/WUV coating samples was shown in Figure 2. It could be seen from Figure 2A and 2B that the surface of WUV was smooth and covered by a uniform and continuous WUV, with a few nanoparticles distributed on the surface. It could be seen from Figure 2C that, at a magnification of 250, the surface of ZnSt2/WUV coating was evenly arranged with micron-sized bulbous flower clusters, indicating that under the adhesive effect of WUV and the modification effect of stearic acid, $\mathrm{ZnO}$ NPs reacted with acetic acid solution to form a micro/nano flower-like structure. As could be seen from the Figure 2D, the surface of the micron-scale bulge was evenly arranged with the petal-like mastoid structure. The petal-like mastoid tip had a nanoscale folded structure, which enabled the gas to exist in the structure and lift the droplets when contacting with the water droplets, so that the water droplets cannot penetrate and spread. The micro/nano structure, similar to that of rose petals, was the key reason to the superhydrophobicity of the ZnSt2/WUV coating $[29,54]$.

\subsection{FTIR and XRD}

Figure 3A shows the FTIR spectrum of ZnSt2/WUV. $2869.5 \mathrm{~cm}^{-1}$ corresponded to the symmetric tensile vibration peak of $\mathrm{C}-\mathrm{H}$ bond. 1320.9 and $1164.7 \mathrm{~cm}^{-1}$ were the asymmetric stretching vibration peaks of $\mathrm{C}-\mathrm{O}-\mathrm{C}$, while 1488.7 and $1432.8 \mathrm{~cm}^{-1}$ were the bending vibration peaks of $-\mathrm{CH}_{2} .1376 .9 \mathrm{~cm}^{-1}$ was the symmetric deformation vibration peak of $-\mathrm{CH}_{3}$. The absorption peaks corresponding to the reaction products $-\mathrm{CH}_{2}$ and $-\mathrm{CH}_{3}$ were 2923.5 and $2850.2 \mathrm{~cm}^{-1}$, respectively. It can be seen that the amount of $\mathrm{C}$ element and alkyl on the surface of ZnSt2/WUV increased significantly, indicating that the coating had been modified by stearic acid. The XRD pattern of the ZnSt2/WUV was shown in Figure 3B. It could be seen that the characteristic diffraction peak of zinc contained a small amount of $\mathrm{C}$ and $\mathrm{O}$ elements. In Figure $3 \mathrm{~B}$, the peaks at $16.2^{\circ}, 22.6^{\circ}$, and $33.2^{\circ}$ corresponded to the peaks of zinc stearate crystals. This indicated that the modification of stearic acid promotes the changes in topography of the surface and the formation of nano-particles, the carboxyl group in acetic acid reacted 
with $\mathrm{ZnO}$ particles, and the $-\mathrm{CH}_{3}$ hydrophobic group was grafted onto the surface of $\mathrm{ZnSt} 2$ particles, successfully constructing the superhydrophobic coating on the surface of poplar wood.

A

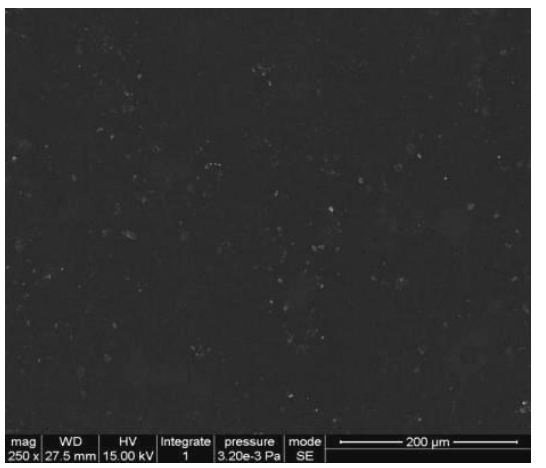

C

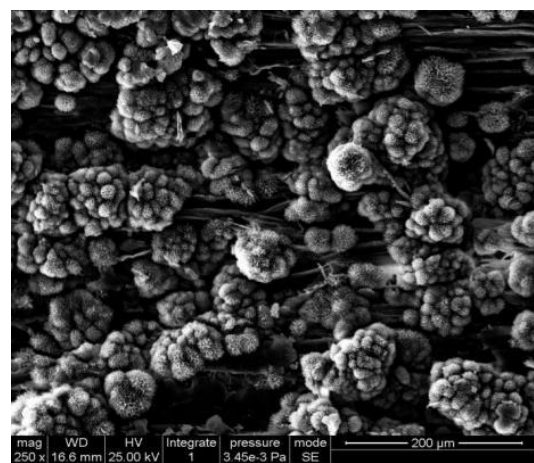

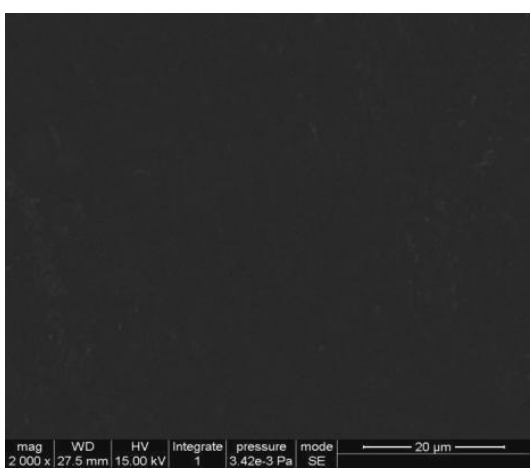

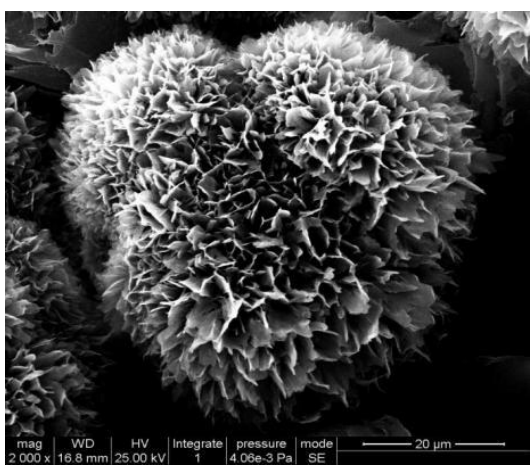

B

$\mathrm{D}$

Figure 2. SEM images of WUV (A: at 250 magnification; B: at 2000 magnification) and ZnSt2/WUV (C: at 250 magnification; D: at 2500 magnification) coatings.
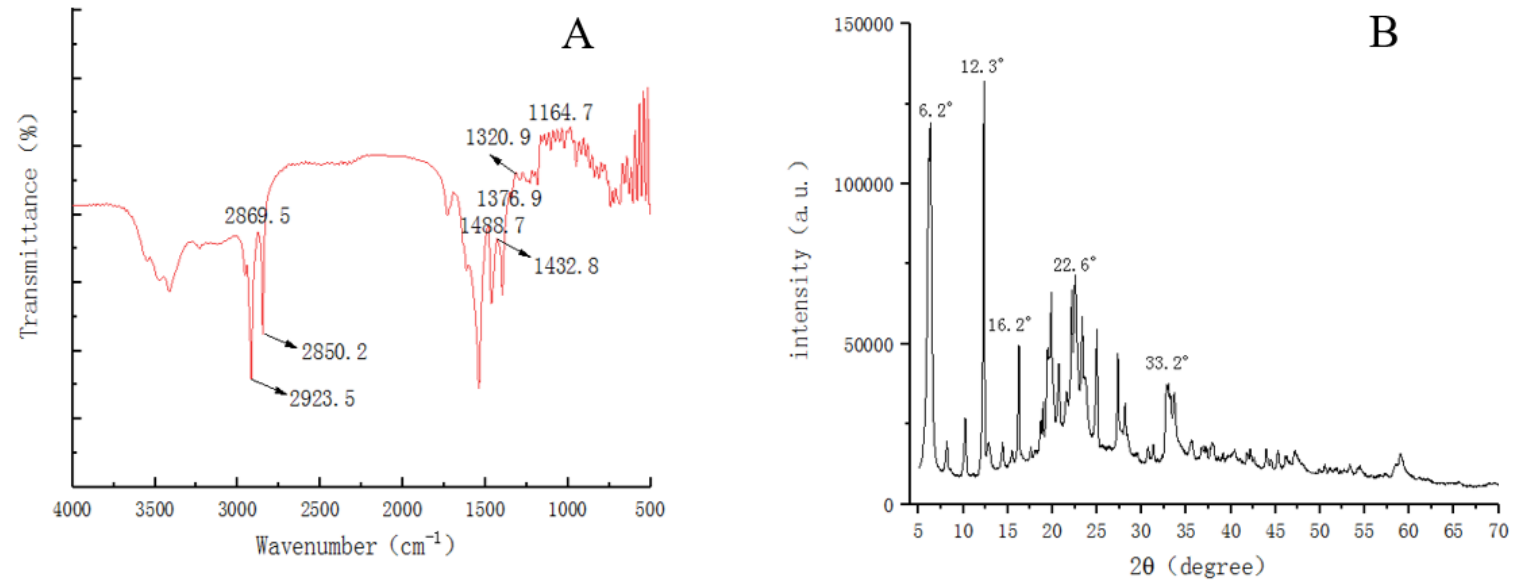

Figure 3. FTIR (A) and XRD (B) of ZnSt2/WUV.

\subsection{Different $p H$ Values of Solution and Organic Solvent Immersion Test}

The water contact angle of the water on ZnSt2/WUV coating was measured after impregnated in different $\mathrm{pH}$ values of solution and organic solvent. As could be seen from Figure $4 \mathrm{~A}$, the CA of coating was greater than $150^{\circ}$ after being soaked in the solutions with $\mathrm{pH}$ values of 2,4 , and 7 for $50 \mathrm{~h}$. After soaking in the solutions with $\mathrm{pH}$ values of 2,4 , and 7 for $100 \mathrm{~h}$, the CA was greater than $140^{\circ}$, this was owing to the $\mathrm{ZnSt} 2 / \mathrm{WUV}$ coating decompose into stearic acid and corresponding salt when it encounters acid, and its hydrophobicity would not lose, indicating its ability to maintain hydrophobicity in acid solution and neutral solution. The superhydrophobic property of the ZnSt2/WUV coating lost after impregnating in the solution with $\mathrm{pH}$ values of 9 for $15 \mathrm{~h}$ and $12 \mathrm{for} 5 \mathrm{~h}$, respectively. 
This indicated that it is difficult for ZnSt2/WUV coating to maintain hydrophobicity in alkaline solution for a long time. The contact angle was above $140^{\circ}$ after the ZnSt2/WUV coating was impregnated for $60 \mathrm{~h}$ in the solution with $\mathrm{pH}$ value of 9 and the contact angle was above $140^{\circ}$ after the coating was impregnated in the solution with $\mathrm{pH}$ value of 9 for $3 \mathrm{~h}$. The contact angle of the coating was above $130^{\circ}$ after immersion for $100 \mathrm{~h}$ in the solution with $\mathrm{pH}$ values of 9 and 12 . The results showed that the surface of the sample was still hydrophobic after dipping with the alkaline solution, the hydrophobicity of ZnSt2/WUV can be well maintained in acidic medium. As shown in Figure 4B, because the ethyl alcohol and n-hexane used for impregnation was neutral and acetic acid was said to be acidic, the ZnSt2/WUV coating remained super-hydrophobic after being impregnated in the solution of n-ethane, anhydrous ethanol, and acetic acid for $50 \mathrm{~h}$, respectively. The stability of ZnSt2/WUV coating in ethyl acetate and tetrabutyl titanate solutions-which all present alkaline after hydrolysis—was relatively poor, which might be due to the reason that the low surface energy material on the coating surface was easy to dissolve in alkaline organic solvent, resulting in the loss of superhydrophobicity of the coating. In Figure 4A, the R2 coefficient of the contact angle of water on ZnSt2/WUV with the immersion time is -0.93 , and in Figure 4B, the R2 coefficient of the contact angle of water on ZnSt2/WUV with the immersion time is -0.94 . It can be seen that there is a negative correlation between the contact angle of water on ZnSt2/WUV and the immersion time. In a word, the coating could be better to maintain its hydrophobicity in acid organic solvents. Therefore, the application of this superhydrophobic coating onto wood surface could protect wood from erosion when it is exposed to an acid or alkaline environment, and extend the use of poplar wood.
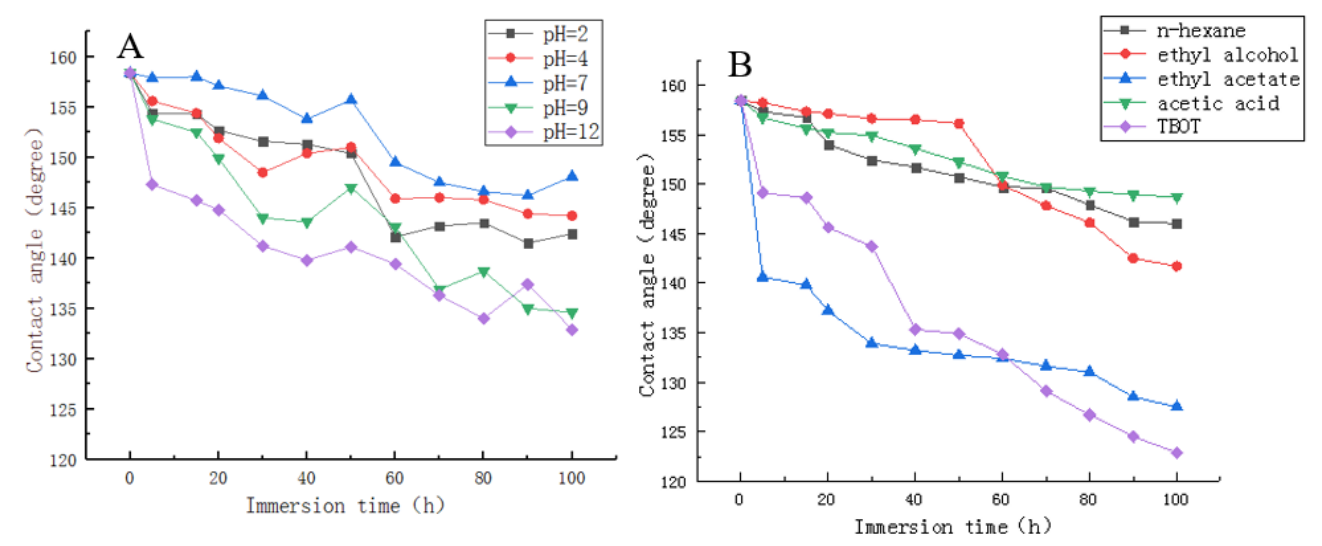

Figure 4. Different $\mathrm{pH}$ values of solution and organic solvent immersion test of ZnSt2/WUV (A: immersion in different $\mathrm{pH}$ solutions; $\mathbf{B}$ : immersion in different organic solvent).

\subsection{Water Resistance Test}

The water resistance test results of WUV and ZnSt2/WUV coatings are shown in Figure 5. WUV and ZnSt2/WUV was soaked in distilled water for 45 days. The water absorption rate increased with the increase of days and the water absorption of WUV went up even more and faster. When the samples were immersed in water for 45 days, the absorption rate of the WUV coating increased from $6.1 \%$ to $88.9 \%$, while that of the ZnSt2/WUV increased from $0.9 \%$ to $67.8 \%$. It could be seen that the ZnSt2/WUV showed good water resistance. This is because the modification of stearic acid constructed a super-hydrophobic structure of multigrade $\mathrm{ZnO}$ on the surface of poplar wood, so that the wood surface containing hygroscopicity components was covered by $\mathrm{ZnSt2}$, which reduced the hygroscopicity of poplar wood. According to the test, after 50 days of immersion in distilled water, the contact angle of water on the surface of the sample was $154.4^{\circ}$, which showed a persistent superhydrophobicity [53]. Therefore, this method of constructing superhydrophobic coatings on the surface of wood substrates was expected to expand the use of poplar wood in waterproof and stain resistant [55]. 


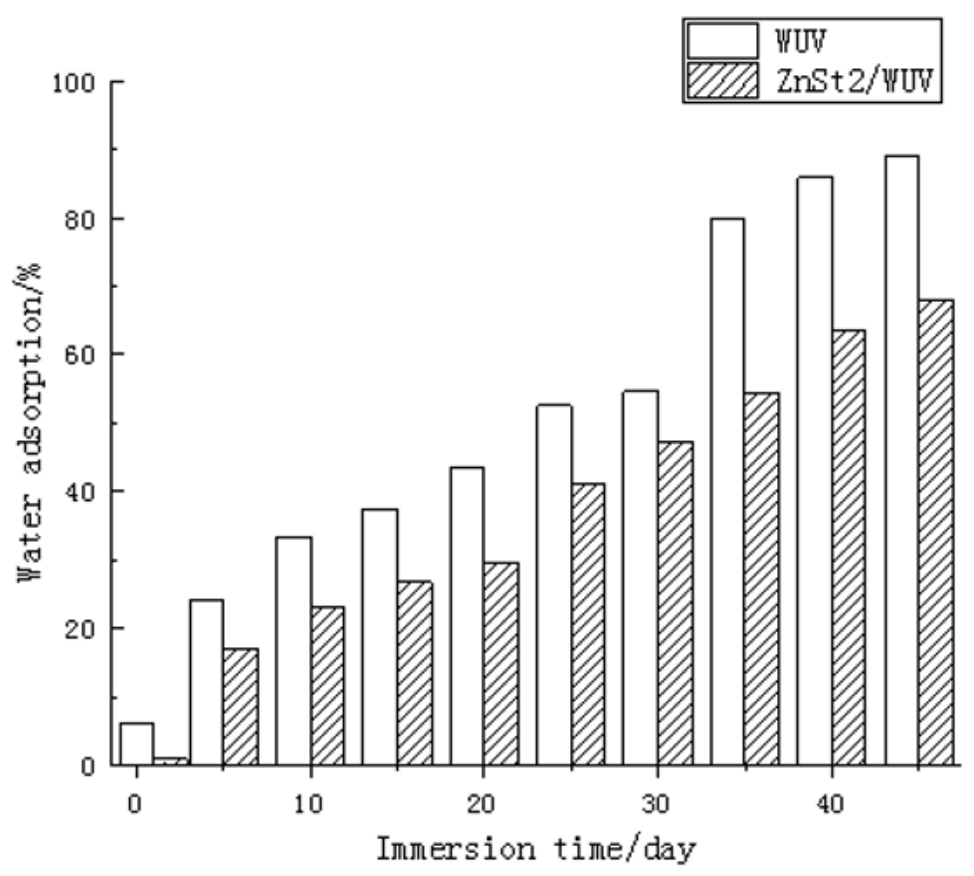

Figure 5. Water resistance test of WUV and ZnSt2/WUV.

\section{Conclusions}

A superhydrophobic coating was constructed on the surface of poplar wood with a contact angle of up to $158.4^{\circ}$ through the water-based UV-cured wood coating which was modified by $\mathrm{ZnO}$ and stearic acid. The results showed that under acid condition, the nonpolar long chain alkyl group of stearic acid vapor molecule reacted with the hydroxyl group in acetic acid, the metal ions of the $\mathrm{ZnO}$ were displaced to the stearic acid and generated globular zinc stearate $\left(\mathrm{C}_{36} \mathrm{H}_{70} \mathrm{O}_{4} \mathrm{Zn}\right)$. $-\mathrm{CH}_{3}$ hydrophobic groups were grafted to the surface of $\mathrm{ZnSt} 2$ particles and micro/nano level of multistage flower $\mathrm{ZnSt2}$ coarse structure was successfully constructed on the surface of poplar wood, which was the key to the superhydrophobic property of the coating. The $\mathrm{pH}$, corrosion resistance, and water resistance tests revealed that the ZnSt2/WUV coating had good resistance to acid medium and some organic solvent corrosion ability. Compared with WUV, the water resistance of ZnSt2/WUV was stronger, which was conducive to prepare superhydrophobic coatings in an easy and environmentally friendly way and expand the application scope of poplar products in waterproof field.

Author Contributions: Conceptualization, Y.W.; Data curation, X.W.; Funding acquisition, Y.W., F.Y. and J.Y.; Methodology, X.W.; Resources, F.Y.; Writing—original draft, X.W.; Writing—review \& editing, Y.W. All authors have read and agreed to the published version of the manuscript.

Funding: The authors gratefully acknowledgement the financial support from the project funded by "Nan Taihu Lake elite plan" project ([2018] no. 2), the Special Scientific Research Fund of Construction of High-level teachers Project of Beijing Institute of Fashion Technology (BIFTQG201805), the Project of Science and Technology Plan of Beijing Municipal Education Commission (KM202010012001), and Yihua Lifestyle Technology Co., Ltd. Projects funded (YH-NL-201507 and YH-JS-JSKF-201904003).

Acknowledgments: The authors gratefully acknowledgement the financial support from China and would like to thank Shang Huang for helping us prepare the samples.

Conflicts of Interest: The authors declare no conflict of interest.

\section{References}

1. Yan, X.; Qian, X.; Chang, Y. Preparation and characterization of urea formaldehyde@ epoxy resin microcapsule on waterborne wood coatings. Coatings 2019, 9, 475. [CrossRef]

2. Wang, N.; Zhang, Y.; Chen, J.; Zhang, J.; Fang, Q. Dopamine modified metal-organic frameworks on anti-corrosion properties of waterborne epoxy coatings. Prog. Org. Coat. 2017, 109, 126-134. [CrossRef] 
3. Xu, W.; Fang, X.Y.; Han, J.T.; Wu, Z.H.; Zhang, J.L. Effect of coating thickness on sound absorption property of four wood species commonly used for piano soundboards. Wood Fiber Sci. 2020, 52, 28-43. [CrossRef]

4. Yan, X.; Qian, X.; Lu, R.; Miyakoshi, T. Comparison and optimization of reactive dyes and coating performance on fraxinus mandshurica veneer. Polymers 2018, 10, 1302. [CrossRef]

5. Shahriari, L.; Mohseni, M.; Yahyaei, H. The effect of cross-linking density on water vapor and oxygen permeability of hybrid UV cured nano coatings. Prog. Org. Coat. 2019, 134, 66-77. [CrossRef]

6. Aizpurua, J.; Martin, L.; Fernández, M.; González, A.; Irusta, L. Recyclable, remendable and healing polyurethane/acrylic coatings from UV curable waterborne dispersions containing Diels-Alder moieties. Prog. Org. Coat. 2020, 139, 105460. [CrossRef]

7. Wang, S.; Wu, Y.; Dai, J.; Teng, N.; Peng, Y.; Cao, L.; Liu, X. Making organic coatings greener: Renewable resource, solvent-free synthesis, UV curing and repairability. Eur. Polym. J. 2020, 123, 109439. [CrossRef]

8. Yan, X.; Qian, X.; Chang, Y.; Lu, R.; Miyakoshi, T. The effect of glass fiber powder on the properties of waterborne coatings with thermochromic ink on a Chinese Fir surface. Polymers 2019, 11, 1733. [CrossRef]

9. Rawat, R.S.; Chouhan, N.; Talwar, M.; Diwan, R.K.; Tyagi, A.K. UV coatings for wooden surfaces. Prog. Org. Coat. 2019, 135, 490-495. [CrossRef]

10. Xiong, X.Q.; Yuan, Y.Y.; Niu, Y.T.; Zhang, L.T.; Wu, Z.H. Effects of different treatments on surface activity of rice straw particleboard. Sci. Adv. Mater. 2020, 12, 289-295. [CrossRef]

11. Nosrati, R.; Olad, A.; Maryami, F. Visible-light induced anti-bacterial and self-cleaning waterborne polyacrylic coating modified with $\mathrm{TiO}_{2}$ /polypyrrole nanocomposite; preparation and characterization. J. Mol. Struct. 2018, 1163, 174-184. [CrossRef]

12. Wu, Y.; Sun, Y.; Yang, F.; Zhang, H.; Wang, Y. The implication of benzene-ethanol extractive on mechanical properties of waterborne coating and wood cell wall by nanoindentation. Coatings 2019, 9, 449. [CrossRef]

13. Hang, T.T.X.; Anh, N.T.; Truc, T.A.; Van Truoc, B.; Hoang, T.; Thanh, D.T.M.; Daopiset, S. Synthesis of 3-glycidoxypropyltrimethoxysilane modified hydrotalcite bearing molybdate as corrosion inhibitor for waterborne epoxy coating. J. Coat. Technol. Res. 2016, 13, 805-813. [CrossRef]

14. $\mathrm{Xu}, \mathrm{R} . ; \mathrm{He}, \mathrm{T}$. Corrosion of self-curing waterborne zinc oxide-potassium silicate coating modified with aluminium powder. J. Alloy. Compd. 2019, 811, 152008. [CrossRef]

15. Zhong, S.; Li, J.; Yi, L.; Cai, Y.; Zhou, W. Cross-linked waterborne alkyd hybrid resin coatings modified by fluorinated acrylate-siloxane with high waterproof and anticorrosive performance. Polym. Adv. Technol. 2019, 30, 292-303. [CrossRef]

16. Saladino, M.L.; Motaung, T.E.; Luyt, A.S.; Spinella, A.; Nasillo, G.; Caponetti, E. The effect of silica nanoparticles on the morphology, mechanical properties and thermal degradation kinetics of PMMA. Polym. Degrad. Stab. 2012, 97, 452-459. [CrossRef]

17. Zhu, W.; Wu, Y.; Zhang, Y. Synthesis and characterisation of superhydrophobic CNC/ZnO nanocomposites by using stearic acid. Micro Nano Lett. 2019, 14, 1317-1321. [CrossRef]

18. Zhong, W.L. Structure distortion, optical and electrical properties of $\mathrm{ZnO}$ thin films co-doped with $\mathrm{Al}$ and $\mathrm{Sb}$ by sol-gel spin coating. Chin. Geogr. 2010, 19, 515-519.

19. Ismail, A.; Alahmad, M.; Alsabagh, M.; Abdallah, B. Effect of low dose-rate industrial Co-60 gamma irradiation on $\mathrm{ZnO}$ thin films: Structural and optical study. Microelectron. Reliab. 2020, 104, 113556. [CrossRef]

20. Shalu, C.; Shukla, M.; Tiwari, A.; Agrawal, J.; Bilgaiyan, A.; Singh, V. Role of solvent used to cast P3HT thin films on the performance of $\mathrm{ZnO} / \mathrm{P} 3 \mathrm{HT}$ hybrid photo detector. Phys. E Low-Dimens. Syst. Nanostruct. 2020, 15, 113694. [CrossRef]

21. Wang, Z.; Liu, F.; Han, E.; Ke, W.; Luo, S. Effect of ZnO nanoparticles on anti-aging properties of polyurethane coating. Sci. Bull. 2009, 54, 3464-3472. [CrossRef]

22. Qu, J.E.; Ascencio, M.; Jiang, L.M.; Omanovic, S.; Yang, L.X. Improvement in corrosion resistance of WE43 magnesium alloy by the electrophoretic formation of a $\mathrm{ZnO}$ surface coating. J. Coat. Technol. Res. 2019, 16, 1559-1570. [CrossRef]

23. Lin, J.; Chen, C.; Lin, C. Influence of sol-gel-derived $\mathrm{ZnO}: \mathrm{Al}$ coating on luminescent properties of $\mathrm{Y}_{2} \mathrm{O}_{3}: \mathrm{Eu}^{3+}$ phosphor. J. Sol-Gel Sci. Technol. 2019, 92, 562-574. [CrossRef]

24. Yadav, A.B.; Pandey, A.; Jit, S. Effects of annealing temperature on the structural, optical, and electrical properties of $\mathrm{ZnO}$ thin films grown on $\mathrm{n}-\mathrm{Si}\langle 100\rangle$ substrates by the sol-gel spin coating method. Acta Metall. Sin. 2014, 27, 682-688. [CrossRef] 
25. Hussain, F.; Imran, M.; Khalil, R.M.A.; Niaz, N.A.; Rana, A.M.; Sattar, M.A.; Ismail, M.; Majid, A.; Kim, S.; Iqbal, F.; et al. An insight of $\mathrm{Mg}$ doped $\mathrm{ZnO}$ thin films: A comparative experimental and first-principle investigations. Phys. E Low-Dimens. Syst. Nanostruct. 2020, 115, 113658. [CrossRef]

26. Saleem, M.; Farooq, W.A.; Khan, M.I.; Akhtar, M.N.; Rehman, S.U.; Ahmad, N.; Khalid, M.; Atif, M.; AlMutairi, M.A.; Irfan, M. Effect of ZnO nanoparticles coating layers on top of ZnO Nanowires for morphological, optical, and photovoltaic properties of dye-sensitized solar cells. Micromachines 2019, 10, 819. [CrossRef]

27. Kumar, V.; Ntwaeaborwa, O.M.; Swart, H.C. Effect of oxygen partial pressure during pulsed laser deposition on the emission of Eu doped $\mathrm{ZnO}$ thin films. Phys. B Condens. Matter 2020, 576, 411713. [CrossRef]

28. Srisuai, N.; Boonruang, S.; Horprathum, M.; Sarapukdee, P.; Denchitcharoen, S. Growth of highly uniform size-distribution $\mathrm{ZnO}$ NR arrays on sputtered $\mathrm{ZnO}$ thin film via hydrothermal with PMMA template assisted. Mater. Sci. Semicond. Process. 2020, 105, 104736. [CrossRef]

29. Zhu, W.; Wu, Y.; Zhang, Y. Fabrication and characterization of superhydrophobicity ZnO nanoparticles with two morphologies by using stearic acid. Mater. Res. Express 2019, 6, 1150d1. [CrossRef]

30. Sharifalhoseini, Z.; Entezari, M.H.; Davoodi, A.; Shahidi, M. Surface modification of mild steel before acrylic resin coating by hybrid $\mathrm{ZnO} / \mathrm{GO}$ nanostructures to improve the corrosion protection. J. Ind. Eng. Chem. 2020, 83, 333-342. [CrossRef]

31. Zhou, J.; Li, K.; Wang, B.; Ai, F. Nano-hydroxyapatite/ZnO coating prepared on a biodegradable Mg-Zn-Ca bulk metallic glass by one-step hydrothermal method in acid situation. Ceram. Int. 2020, 46, 6958-6964. [CrossRef]

32. Guo, H.; Michen, B.; Burgert, I. Estudios reales en banco de pruebas de la Casa ETH de Recursos Naturales protección superficial de la madera para aplicaciones exteriores. Inf. Constr. 2017, 69, 220. [CrossRef]

33. Nair, S.; Nagarajappa, G.B.; Pandey, K.K. UV stabilization of wood by nano metal oxides dispersed in propylene glycol. J. Photochem. Photobiol. B Biol. 2018, 183, 1-10. [CrossRef] [PubMed]

34. Mishra, P.K.; Giagli, K.; Tsalagkas, D.; Mishra, H.; Talegaonkar, S.; Gryc, V.; Wimmer, R. Changing Face of Wood Science in Modern Era: Contribution of Nanotechnology. Recent Pat. Nanotechnol. 2018, 12, $13-21$. [CrossRef] [PubMed]

35. Tuong, V.M.; Chu, T.V. Improvement of color stability of acacia hybrid wood by $\mathrm{TiO}_{2}$ nano sol impregnation. BioResources 2015, 10, 5417-5425. [CrossRef]

36. Yu, Y.; Jiang, Z.; Wang, G.; Song, Y. Growth of ZnO nanofilms on wood with improved photostability. Holzforschung 2010, 64, 385-390. [CrossRef]

37. Zhang, J.; Zhang, W.; Lu, J.; Zhu, C.; Lin, W.; Feng, J. Aqueous epoxy-based superhydrophobic coatings: Fabrication and stability in water. Prog. Org. Coat. 2018, 121, 201-208. [CrossRef]

38. Jia, S.; Lu, X.; Luo, S.; Qing, Y.; Yan, N.; Wu, Y. Efficiently texturing hierarchical epoxy layer for smart superhydrophobic surfaces with excellent durability and exceptional stability exposed to fire. Chem. Eng. J. 2018, 348, 212-223. [CrossRef]

39. Jeong, J.H.; Han, Y.C.; Yang, J.H.; Kwak, D.S.; Jeong, H.M. Waterborne polyurethane modified with poly(ethylene glycol) macromer for waterproof breathable coating. Prog. Org. Coat. 2017, 103, 69-75. [CrossRef]

40. Grüneberger, F.; Künniger, T.; Huch, A.; Zimmermann, T.; Arnold, M. Nanofibrillated cellulose in wood coatings: Dispersion and stabilization of ZnO as UV absorber. Prog. Org. Coat. 2015, 87, 112-121. [CrossRef]

41. Miklečić, J.; Turkulin, H.; Jirouš-Rajković, V. Weathering performance of surface of thermally modified wood finished with nanoparticles-modified waterborne polyacrylate coatings. Appl. Surf. Sci. 2017, 408, 103-109. [CrossRef]

42. Yu, D.; Wen, S.; Yang, J.; Wang, J.; Chen, Y.; Luo, J.; Wu, Y. RGO modified ZnAl-LDH as epoxy nanostructure filler: A novel synthetic approach to anticorrosive waterborne coating. Surf. Coat. Technol. 2017, 326, 207-215. [CrossRef]

43. Wang, S.; Hu, Z.; Shi, J.; Chen, G.; Zhang, Q.; Weng, Z.; Wu, K.; Lu, M. Green synthesis of graphene with the assistance of modified lignin and its application in anticorrosive waterborne epoxy coatings. Appl. Surf. Sci. 2019, 484, 759-770. [CrossRef]

44. Dong, H.; Zheng, L.; Yu, P.; Jiang, Q.; Wu, Y.; Huang, C.; Yin, B. Characterization and Application of Lignin-Carbohydrate Complexes from Lignocellulosic Materials as Antioxidants for Scavenging In Vitro and In Vivo Reactive Oxygen Species. ACS Sustain. Chem. Eng. 2020, 8, 256-266. [CrossRef] 
45. Sun, S.; Zhao, Z.; Umemura, K. Further Exploration of Sucrose-Citric Acid Adhesive: Synthesis and Application on Plywood. Polymers 2019, 11, 1875. [CrossRef] [PubMed]

46. Zhao, Z.; Sun, S.; Wu, D.; Zhang, M.; Huang, C.; Umemura, K.; Yong, Q. Synthesis and characterization of sucrose and ammonium dihydrogen phosphate (SADP) adhesive for plywood. Polymers 2019, 11, 1909. [CrossRef] [PubMed]

47. Yang, M.; Chen, X.; Lin, H.; Han, C.; Zhang, S. A simple fabrication of superhydrophobic wood surface by natural rosin based compound via impregnation at room temperature. Eur. J. Wood Wood Prod. 2018, 76, 1417-1425. [CrossRef]

48. Gao,H.; Duan, Y.; Yuan, Z. Preparation and oil-water separation performance of ultra-hydrophilic subaqueous ultra-hydrophobic pvdf-g-paa porous membrane. Acta Chem. Sin. 2016, 37, 1208-1215.

49. Wang, S.; Shi, J.; Liu, C.; Xie, C.; Wang, C. Fabrication of a superhydrophobic surface on a wood substrate. Appl. Surf. Sci. 2011, 257, 9362-9365. [CrossRef]

50. Zhao, Z.; Sakai, S.; Wu, D.; Chen, Z.; Zhu, N.; Gui, C.; Zhang, M.; Umemura, K.; Yong, Q. Investigation of synthesis mechanism, optimal hot-pressing conditions, and curing behavior of sucrose and ammonium dihydrogen phosphate adhesive. Polymers 2020, 12, 216. [CrossRef]

51. Wei, X.; Li, Q.; Hao, H.; Yang, H.; Li, Y.; Sun, T.; Li, X. Preparation, physicochemical and preservation properties of $\mathrm{Ti} / \mathrm{ZnO}$ in situ SiOx chitosan composite coatings. J. Sci. Food Agric. 2019, 100, 570-577. [CrossRef] [PubMed]

52. He, Y.; Wan, M.; Wang, Z.; Zhang, X.; Zhao, Y.; Sun, L. Fabrication and characterization of degradable and durable fluoride-free super-hydrophobic cotton fabrics for oil/water separation. Surf. Coat. Technol. 2019, 378, 125079. [CrossRef]

53. Pandey, S.; Singh, S.P. Organic solvent tolerance of an $\alpha$-Amylase from haloalkaliphilic bacteria as a function of $\mathrm{pH}$, temperature, and salt concentrations. Appl. Biochem. Biotechnol. 2012, 166, 1747-1757. [CrossRef]

54. Wang, C.; Tzeng, F.; Chen, H.; Chang, C. Ultraviolet-durable superhydrophobic zinc oxide-coated mesh films for surface and underwater-oil capture and transportation. Langmuir 2012, 28, 10015-10019. [CrossRef] [PubMed]

55. Cai, P.; Bai, N.; Xu, L.; Tan, C.; Li, Q. Fabrication of superhydrophobic wood surface with enhanced environmental adaptability through a solution-immersion process. Surf. Coat. Technol. 2015, 277, 262-269. [CrossRef] 